\title{
Erratum: An Environmental Decision Support System for Water Issues in the Oil Industry
}

\author{
Ralf Denzer ${ }^{1}$, Fernando Torres-Bejarano ${ }^{2}$, Thorsten Hell ${ }^{3}$, Steven Frysinger ${ }^{1,4}$, \\ Sascha Schlobinski ${ }^{3}$, Reiner Güttler ${ }^{1}$, and Hermilo Ramírez ${ }^{2}$ \\ ${ }^{1}$ Environmental Informatics Group (EIG), Goebenstrasse 40, 66117 Saarbrücken, Germany \\ ${ }^{2}$ Mexican Petroleum Institute (IMP), Eje Central Lázaro Cárdenas \\ 152 Mexico D.F., Mexico \\ 3 cismet GmbH, Altenkesseler Strasse 17, 66115 Saarbrücken \\ ${ }^{4}$ James Madison University, Harrisonburg, Virginia, USA 22807 \\ ralf.denzer@enviromatics.org
}

J. Hřebíček, G. Schimak, and R. Denzer (Eds.): ISESS 2011, IFIP AICT 359, pp. 208-216, 2011.

(C) IFIP International Federation for Information Processing 2011

DOI 10.1007/978-3-642-22285-6_73

The name of the second author is "Franklin Torres-Bejarano" and not, as stated by mistake, "Fernando Torres-Bejarano". 